\title{
TELAS, JANELAS \& VITRINES: O ESPETÁCULO E O VOYEURISMO EM STELLA MANHATTAN
}

Bobby J. Chamberlain University of Pittsburgh

À memória de Francisco Caetano Lopes Júnior

\section{I}

$\mathbf{E}$

m ensaio publicado em 1986, a crítica brasileira Flora Süssekind destacou a presença, numa série de romances e contos dos anos 80, da observação, da descrição ou da narração através de telas (de cinema, de televisão, de monitores de computador), janelas, vitrines, vidraças, espelhos etc. ${ }^{1}$ Afirmou que o emprego de tais técnicas e de outras afins, como o aproveitamento de outdoors, lentes deformadoras e videoclipes, vem reforçar a noção da vida como espetáculo e do papel do leitor como voyeur, assim apagando a fronteira entre vida pública e vida particular como se todos fossem astros de celulóide cujas vidas íntimas e públicas se projetassem promiscuamente na tela grande ou na pequena.

Já, em outro artigo, identificamos tal fenômeno como um dos carros-chefe da estética pós-moderna na ficção brasileira, citando, a título de exemplos, obras como Zero, de Ignácio de Loyola Brandão (1974), Bufo \& Spallanzani, de Rubem Fonseca (1985) e Stella Manhattan, de Silviano Santiago (1985). ${ }^{2}$ Se, na primeira delas, aparece e reaparece uma ubíqua, e decididamente sinistra, "tela incandescente" (entenda-se por isso, suponhamos, tela de televisão),

\footnotetext{
${ }^{1}$ SÜSSEKIND, 1986, p.82-89.

${ }^{2}$ CHAMBERLAIN, 1993, p.593-604.
} 
bem como uma figura humana que lembra um rato a espiar repetidamente pelas frinchas de um labirinto, nem por isso as outras duas deixam de se preocupar, à sua maneira, com a presença de simulacros tradicionais e atuais. Em Bufo, por exemplo, Fonseca justapõe as obras literárias de autores europeus e americanos (!) do século XIX, relatos históricos de experiências científicas e sua própria narração detetivesca e notas de rodapé espúrias, com reportagens policiais televisivas e comandos de computador no inglês original.

Silviano preocupa-se ainda mais, a nosso ver, com tais técnicas em Stella Manhattan. Logo de início, a protagonista Stella, alter ego do empregado consular brasileiro Eduardo da Costa e Silva, identifica-se intimamente com o espetáculo e a teatralidade, não só pelos gestos extravagantes, poses histriônicas e comparação com os outdoors da paisagem urbana circunstante, como também - e talvez até muito mais - pelo seu costume matinal de pavonear diante da janela do apartamento nova-iorquino e dos ávidos olhos de um casal de abelhudos vizinhos americanos. Além disso, o voyeurismo vincula-se, em outras passagens do romance, com o prazer sexual vicário, especificamente na relação do professor Aníbal Paes Leme - condenado desde jovem a passar a vida numa cadeira de rodas - com a sua mulher Leila.

A tais obras, poder-se-ia acrescentar, diga-se de passagem, os romances e contos de João Gilberto Noll, muitos contos de Edilberto Coutinho, alguns livros de Sérgio Sant'Anna, o Estorvo, de Chico Buarque (1991) - com o seu mundo visto através do olho mágico da porta de um apartamento carioca - e o Sangue de Coca-Cola, de Roberto Drummond (1982). Ou mesmo o romance final de Clarice Lispector, A bora da estrela (1977), no qual o narrador dramatizado da história Rodrigo S.M. é sempre pintado como um espectador e representador da desgraçada Macabéa, um misto de subalterna debaixo do limiar da escrita e da própria fala e, ironicamente, êmula vicária dos glamourosos filmes de Hollywood. Abundam os exemplos.

Pretendo me concentrar, nos parágrafos que se seguem, em Stella Manhattan, romance que considero como um dos melhores 
exemplares, nos últimos anos, de algumas das supracitadas técnicas. Começarei aprofundando e pormenorizando um pouco mais algumas das caracterizações já referidas para falar depois das possíveis implicações de cada uma. Espero, destarte, poder entrosálas num esquema que dê conta da estreita inter-relação entre as várias manifestações da estética do espetáculo, com seus desvios nos âmbitos da propaganda e da televisão, e a do voyeurismo, ligado tão intimamente à psicologia e à problemática do observador.

\section{II}

O romance começa com a Stella a desfilar diante da janela do apartamento. Primeiro, ela a abre a fim de deixar entrar o ar frio e poluído de uma manhã de outono de Nova Iorque, para, logo em seguida, se lembrar do calor e mormaço do seu saudoso Rio de Janeiro, do qual se encontra atualmente exilada. Cantando e suspirando, enquanto se compara a um outdoor de cigarros da Times Square,

[ela] expira e abre os braços como vedete na apoteose final de teatro de revista da Tiradentes e, se tivesse uma escada na sua frente, galgaria degrau após degrau entre plumas, strass e paetês, luxuosamente, luxuriosamente galgaria os degraus até chegar ao topo de onde em afinado e longo trinado, jogando beijos e mais beijos para os admiradores que gritam em delírio: "É a maior! é a maior!", de onde tremularia a voz num agudo que ribombaria pelas abóbadas no céu de Manhattan sob os aplausos frenéticos da platéia. Stella Manhattan: Estrela de Manhattan. (p.12-13)

Irrompe em cena, desde o princípio, o olhar desdenhoso da velha vizinha:

Stella percebe, como não ia deixar de perceber? a velha vizinha de frente que o observa entre assustada e medrosa por detrás da vidraça do seu apartamento. Esta comenta o teatrinho matinal de Stella no palco da janela aberta, comenta-o com gestos e palavras dirigidos ao marido entrevado na cama, e conclui:

"He's nuts."

"Who's nuts?"

"The Puerto-rican who lives in the building across the street." (p.12) 
Stella, cantarolando uma música de Carnaval, logo desvia a atenção da odiada gringa e de lembranças da véspera do seu próprio namorado americano Ricky para as tarefas mundanas da faxina doméstica no momento atual. Ao longo desta seqüência, ela é representada como se fosse uma artista a atuar numa peça musical ou revista, seja para os olhos dos vizinhos, seja para os imaginários admiradores da Cinelândia. "Stella amanheceu louca louca de alegria neste sábado. Mal se continha dentro do apartamento, precisava de palco, refletores e platéia”. (p.14)

Cabe notar que o autor emprega conscientemente comparações e alusões ao teatro e à representação. A janela do apartamento é comparada explicitamente com uma platéia ao passo que a autocomparação da protagonista com uma artista do chamado "teatro rebolado" e também com a propaganda de cigarros, bem como a menção pelo narrador de palavras como "teatrinho", "palco", "refletores" e "público", servem claramente para evocar a esfera do espetáculo. O arroubo da Stella termina abruptamente, porém, quando um porta-retrato é derrubado por um golpe de vento repentino, estraçalhando-se todo no chão do apartamento. Furiosa, Stella fecha a janela num rompante e põe-se logo a focalizar mais criticamente os seus espectadores americanos, como a inverter os papéis de artista e público: ${ }^{3}$

3 Cf. a afirmação bakhtiniana, em Problems of Dostoevsky's Poetics, de que "[o] carnaval é um espetáculo sem ribalta e sem distinção entre artistas e espectadores. No carnaval, todo mundo é participante ativo, todo mundo comunga no ato carnavalesco" (BAKHTIN, p.122). Se bem que não seja a minha intenção aqui recorrer a teorias carnavalescas para explicar a presença do espetáculo e do voyeurismo no romance em apreço, não deixam de ser intrigantes alguns dos evidentes paralelos das técnicas utilizadas em Stella com a estética do excesso, do disfarce, do travestismo, das inversões, e da mistura de "casa" e "rua", assinalados por Roberto Da Matta como sendo típicos do "tríduo de Momo" no Brasil (DA MATTA, passim). 
Detrás da vidraça vê a velha gringa que, também detrás da vidraça, lhe faz caretas e gestos no edifício em frente e faz outras tantas e outros tantos para ela. 'Não brinca, não brinca com Stella, velha megera, porque você não sabe do que ela é capaz. Um dia ainda te torrrce o pescoço.' A velha some por detrás da cortina encardida, sim, ela sabe e como sabe do que Stella é capaz, isso desde o dia em que cruzou com ele na rua e este lhe disse cobras e lagartos, e mais: que deixasse de ser enxerida na vida dos outros, você devia mais é lavar as vidraças e cortinas do seu apartamento, they're as dirty as your mouth, look at them! (p. 13)

Stella passa logo a imaginar-se como uma empregada doméstica, fazendo de conta que amarra um lenço na cabeça, que traja vestidinho de chita e que calça alpercatas havaianas enquanto se prepara para a faxina semanal, com aspirador e vassoura imaginários em riste. Acha-se um misto de Branca de Neve com Sebastiana, a empregada da sua família no Brasil, olhando-se no espelho do banheiro, fazendo poses e admirando-se o tempo todo. Assim Stella parece se converter aqui no seu próprio público, deixando de depender dos enxeridos vizinhos ou dos clientes do imaginário teatro de revista para satisfazer as suas fantasias. Porém, nos últimos parágrafos do romance, quando Eduardo/Stella já desapareceu e nós ficamos tão-somente com as especulações das várias personagens quanto ao seu destino e paradeiro, não é de admirar, talvez, que presenciemos a volta do casal vizinho. De fato, são eles que encerram o romance com um diálogo teatral sobre as prováveis "filiações comunistas" do "porto-riquenho" e que conjeturam sobre a probabilidade do seu assassinato (p. 274-275).

O voyeurismo assume um papel mais patentemente sexual e, ao mesmo tempo, mais explicitamente ideológico no caso de Aníbal e Leila. Caracterizado como um ultra-retrógrado político, racista paranóico e dedo-duro "caçador de comunas", Aníbal é incapaz de ter relações sexuais com a mulher, devido muito mais às suas perversões psicológicas do que às deficiências físicas que, desde a infância, o acorrentaram a uma cadeira de rodas. Não reage em absoluto à nudez e ao exibicionismo da mulher ante seus olhos de espectador dentro do apartamento do casal, só conseguindo se satisfazer sexualmente por meio de um ritual vicário de auto- 
masturbação enquanto a observa, pela janela do apartamento, entregando-se a um estranho qualquer que passe na calçada. Mais uma vez, aparecem elementos do espetáculo nessa performance da Leila, se bem que esta tenha por objetivo, é claro, apenas despertar o apetite sexual do marido voyeur. ${ }^{4}$ Mas, à diferença dos múltiplos gestos e poses da Stella, esta performance provoca a condenação implícita do narrador, já que reflete uma ideologia política nitidamente perversa. Se o exibicionismo da Stella escapa à crítica dirigida satiricamente ao casual espreitador, aqui não se poupa nem voyeur nem "atuante" nos olhos do narrador."

\section{III}

As implicações globais dessa ênfase colocada pelo romance no espetáculo e no voyeurismo nem sempre se patenteiam claramente. Interrelacionam-se, em certa medida, a nosso ver, com as posturas estéticas delineadas pelo narrador-dobradiça no interlúdio ensaístico e metadiscursivo que se segue à segunda seção do romance ("Começo: O Narrador", p. 67-91). ${ }^{6}$ Também, parecem

${ }^{4}$ LOPES JÚNIOR, 1991, p.74, também inclui Leila no rol de personagensdobradiças do romance.

${ }^{5} \mathrm{O}$ exibicionismo em Stella Manhattan, bem como "os arroubos de Artaud diante da beleza do corpo negro semi-exposto do carregador cubano", em Viagem ao México, constituem, para Ana Maria de Bulhões Carvalho EDELWEISS, p.132, exceções ao hábito de Silviano de preferir "o homoerotismo insinuado ao tematizado"; cf. CARVALHO, p.213.

${ }^{6}$ Em pós-escrito ao romance, Silviano acrescenta: "Narrador e personagens dobradiças, homenagem aos 'Bichos', de Lígia Clark, e a 'La Poupée', de Hans Bellmer" (p.277); cf. p.127. No parecer de Francisco Caetano LOPES JÚNIOR, "essa articulação em doublure do romance", presente na cisão das personagens principais, aponta para o caráter paranóico que permeia tanto os agentes de repressão como as vítimas do regime ditatorial (LOPES JÚNIOR, 1988, p.149). Para maiores informações a respeito, veja-se SÜSSEKIND. 
dizer respeito às doutrinas artísticas e ideológicas debatidas energicamente por Marcelo e Aníbal no quarto capítulo (p. 121-37). Da mesma maneira, não deixam de ligar-se com a questão da criação de uma identidade gay, tratada outrossim no romance (p. 211-212), ${ }^{7}$ senão também com a estética camp que tantas vezes - amiúde tão mecanicamente - tem-se identificado com ela.

Parece-me pouco problemática qualquer afirmação da presença de um vínculo íntimo entre a estética do espetáculo, tal e como se manifesta nas performances diárias da Stella, e a tese da arte como excesso, exemplificada na descrição pelo Narrador ${ }_{1}$ do copo de leite transbordante (p. 68-69, 70). Com razão, pode-se dizer outro tanto da relação de ambas as noções com o conceito da arte

Convém assinalar, no tocante ao intervalo do narrador (p.67-91), a preocupação constante deste com as circunstâncias atinentes ao momento de criação da obra de arte. Queixa-se, na voz do Narrador ${ }_{2}$ " "Você [i.e., o Narrador ${ }_{1}$ ] continua a rir de mim e eu pensando como são falsos os romances que só transmitem a continuidade da ação, mas nunca transmitem a desontinuidade da criação" (p.86). As implicações da "especularização" do narrador, assim como outros aspectos do "desdobramento do eu" em Stella, são tratadas por MIRANDA, p.79-84.

7 "Em conversa com Eduardo, Marcelo the disse que a principal característica da bicha hoje é a de uma constante busca de estilo próprio. A diferença entre a bicha e o heterossexual é que este - seja homem ou mulher - já tem estilos de vida codificados, e o processo por assim dizer de amadurecimento nada mais é do que o de assumir um dos estilos já perfeitamente realizados pelas gerações passadas. É por isso, continuava Marcelo, que o heterossexual é tão pouco inventivo quando chega à idade da razão, fala a língua de quase todos, enquanto a bicha atinge a maturidade pelo constante exercício da imaginação em liberdade, inventando cada dia o seu linguajar, que por isso mesmo tem necessariamente de ser pitoresco. A bicha tem de criar um estilo que acaba por ser a maneira como se encaixa sem neurose e com sucesso dentro da comunidade que é obrigatoriamente heterossexual. Para Marcelo, passado e história são coisas que só interessam aos heterossexuais. Bicha acredita é no cotidiano, e é nele que planta os pés como se fosse uma árvore. Sugando tudo o que pode e rapidamente durante a sua passagem pela Terra" (p.211-212). 
baseado no desperdício ou no esforço desperdiçado, conceito esse que o Narrador ${ }_{1}$ identifica com o jazz-band do metrô de Paris (p. 69-71). Também não é despropositado, dentro de tal contexto, sustentar a existência dicotômica de povos que olham para a frente e povos que olham para cima, como faz o Narrador ${ }_{1}$ a seguir (p. 8788 ), ou situar o supracitado debate, travado pelas próprias personagens, entre as modalidades clássica e decadente da arte.

O que me custa relacionar com as noções precedentes, porém, é a asserção subseqüente, feita pelo Narrador ${ }_{1}$, de que a arte verdadeira se fundamenta antes numa economia de esforço, numa espécie de aloofness, ou alienação, da parte do artista e na capacidade deste para abstrair a personalidade da obra por ele criada, capacidade essa que aquele se apressa a identificar com Bob Dylan, Buster Keaton e como uma qualidade essencialmente judaica. É de notar que a última atribuição é criticada taxativamente pelo Narrador $_{2}$ (p. 75-78). Mas, se "[a] arte rejeita a ostentação do luxo, de toda e qualquer acumulação que visa ao poder pelo exibicionismo" (p. 82), como acrescenta o Narrador ${ }_{1}$, como pode se fundamentar simultaneamente no excesso? Ou será esta a contradição na qual o Narrador ${ }_{2}$ logo alega ter caído o Narrador ${ }_{1}$ ?

Ora, tentar vincular tais concepções com a da auto-criação gay ou com alguma estética que se alegue ser essencialmente homossexual, se bem que seja intrigante sob certos prismas, também não chega a ser de todo satisfatório. De fato, poder-se-ia afirmar que, à diferença da teatralidade "perversa" de Aníbal e Leila, a da Stella implica no que Susan Sontag denominou, na sua análise do camp, "o bom gosto do mau gosto", ${ }^{8}$ o qual depende tanto da auto-

${ }^{8}$ SONTAG, 1982, p.105-119. Convém notar que o artigo foi publicado originalmente em 1964. Nele, a autora também afirma a forte relação entre o camp e o espetáculo, o kitsch, e a dupla visão de uma auto-paródia, elementos estéticos que ela associa a uma suposta sensibilidade homossexual. Segundo EDELWEISS, p.139, "Stella Manhattan atinge o camp pelo gosto, gestos e vocabulário do universo gay focalizado, suficientemente marginal e distorcido para satisfazer a essa visão de mundo. Stella Manhattan é camp". 
percepção do artista como da observação do espectador. E, afinal de contas, a tentativa de relacionar isso com a suposta auto-criação de uma identidade gay parece correr o risco de incidir no essencialismo do tipo "bicha é sempre assim mesmo, não é?". A realidade é raramente tão simples.

De qualquer forma, tais interligações, ainda que algumas delas digam respeito às questões vertentes, nem sempre vêm ao caso. Resta perscrutar a especificidade da conexão espetáculo-voyeurismo, por exemplo, assim como as relações de ambos com as "telas, janelas \& vitrines" com as quais começamos.

\section{IV}

Em artigo chamado "O Narrador Pós-Moderno", publicado na Revista do Brasil um ano depois do aparecimento de Stella, Silviano ressalta a importância do narrador-observador, do olhar, do espetáculo e do prazer vicário ao analisar a figura do narrador em alguns contos de Edilberto Coutinho. Nestes, como na ficção pós-moderna em geral, o narrador desempenha, segundo o ensaísta, o papel de um repórter, de um jornalista a contemplar o mundo ao seu redor. Ao invés de contar as próprias experiências ao leitor, como fazia o narrador tradicional, ele é o "narrador que olha" junto com o seu leitor. Um e outro "se definem como espectadores de uma ação alheia que os empolga, emociona, seduz, etc.” (p. 8). Noutras palavras, arma-se uma espécie de palco ou espetáculo, do qual narrador e leitor são meros observadores, ambos a tirarem a sua própria parcela de prazer vicário do drama que se desenrola diante dos seus olhos.?

9 "No conto 'A lugar algum', transcrição ipsis litteris do script de um programa de televisão, em que é entrevistado um jovem marginal, a realidade concreta do narrador é grau zero. Subtraiu-se totalmente. O narrador é todos e qualquer um diante de um aparelho de televisão. [...] Em 'A lugar algum', o narrador é apenas aquele que reproduz. As coisas se passam como se o narrador estivesse apertando o botão do canal de televisão para o leitor". (SANTIAGO, 1986, p.13) 
Como o homem contemporâneo, de quem aliás ele é exímio representante, o narrador do texto pós-moderno não passa, pois, de um

espectador ou de ações vividas ou de ações ensaiadas e representadas. Pelo olhar, homem atual e narrador oscilam entre o prazer e a crítica, guardando sempre a postura de quem, mesmo tendo se subtraído à ação, pensa e sente, se emociona com o que nele resta de corpo e/ou cabeça. [...] Se falta à ação representada o respaldo [abonador] da experiência, esta, por sua vez, passa a ser vinculada ao olhar. A experiência do olhar (p. 12).

Encarada sob esse prisma, a questão do elo a ligar espetáculo com voyeurismo no romance delineia-se mais nitidamente. De acordo com a crítica Maria Antonieta Pereira, o narrador tipo "flâneur parisiense da Modernidade tornou-se [na atualidade pós-moderna] um voyeur nova-iorquino", passando "[d]e cismador a citador" (PEREIRA, p. 11) nesse seu percurso estético-ideológico. Noutras palavras, é o narrador que olha a vida alheia, como afirma o próprio Silviano. Mas é de notar que ele não está sozinho, em Stella Manhattan, nessa condição de "olhador"; acompanham-no, conforme constatamos, tanto leitor quanto personagem. E, como ele, um e outro se distinguem, em grande parte, justamente pelo seu papel de observadores. De fato, a Stella não é, em certo sentido, menos voyeuse do que a abelhuda vizinha da janela ou do que o próprio professor Aníbal a espreitar a mulher adúltera na calçada. Isso não apenas nos momentos em que ela parece inverter os papéis de "observadora" e "observada" com a vizinha, e sim, via de regra, também na sua rotina diária diante da janela e do espelho. Pois Stella também é - vale frisá-lo - espectadora de si mesma, público de suas próprias poses ensaiadas e fantasias narcísicas extravagantes, alvo constante do próprio olhar voyeur.

Mas, à diferença do narrador pós-moderno que o ensaísta identifica nos contos de Edilberto Coutinho, tanto narrador como protagonista, na obra em questão, possuem um olhar duplo, lançado, é claro, em primeiro lugar, ao outro, mas também, simultaneamente, a si mesmos. Sem dúvida, isso advém, em certa medida, da sua qualidade de "dobradiças", comentada por 
Süssekind, Miranda e outros. No caso do narrador, isso não quer dizer, porém, que ele volte a depender exclusivamente das próprias ações vivenciadas e narradas para se arrogar legitimidade, à feição do narrador clássico; autoriza-se, antes, pela sua postura escancaradamente reflexiva, na qual se revela cindido, múltiplo e contraditório, à maneira dos "Bichos" de Lígia Clark. Se ele (Narrador ) $_{1}$ alude ao próprio passado - na forma de reminiscências do metrô de Paris, das músicas de Bob Dylan e das tardes de Nova Iorque em 1970 deitado ao lado de David - também se emaranha constantemente em contradições, desmandando-se na criação de teorias simplistas e até chegando a proferir disparates a respeito dos judeus. Tudo isso é colocado em xeque pelas várias intervenções críticas do Narrador $_{2}$, as quais concorrem para desabonar toda pretensão de autoridade textual calcada na experiência vital do seu interlocutor, por sobre cujos ombros fica olhando o tempo todo.

Quanto a Eduardo/Stella, tal duplicidade - ou multiplicidade no olhar manifesta-se menos no desdobramento da sua identidade genérica do que na sua marcada propensão para o exibicionismo e a auto-observação simultâneos. O caráter performático, ou teatral, do dia-a-dia de Stella patenteia-se, como já vimos, desde a primeira página do romance. Idem, a qualidade exibicionista das suas performances, assim como o grande prazer vicário que ela sente ao representar ou imaginar-se a representar um determinado papel. Ao deleite que recebe de ostentar-se diante dos outros se soma a jouissance de ver-se a si mesma, como a outra, no palco, seja da janela - aqui, uma espécie de vitrine - seja da própria fantasia. O efeito, ao que parece, é cumulativo. É justamente nela, de fato, que se reúnem essas duas tendências da narrativa: o espetáculo e o voyeurismo. Pois, mais do que qualquer outra personagemdobradiça do romance - até mais do que no caso do narradordobradiça - é Stella que amalgama o prurido de observar com o prazer de ser observada. Através de janelas e espelhos, em palcos ilusórios, sobre telas e outdoors imaginários, e sob máscaras diversas, é ela que junta o público ao particular, o artista ao espectador, o estético e o político ao sexual. 


\section{Referências Bibliográficas}

BAKHTIN, Mikhail. Problems of Dostoievsky's Poetics. Trad. Caryl Emerson. Minneapolis: Univ. of Minnesota Press, 1984.

CARVALHO, Ana Maria de Bulhões. Ich Bin Der und Der. In: SOUZA, Eneida Maria de e MIRANDA, Wander Melo (Orgs.). Navegar é preciso: escritos para Silviano Santiago. Belo Horizonte: Editora UFMG; Salvador: EDUFBA; Niterói: EDUFF, 1997, p.197-216.

CHAMBERLAIN, Bobby J. Pós-Modernidade e a ficção brasileira dos anos 70 e 80. Revista Iberoamericana, Pittsburgh, v.59, n.164-165, p.593-604, julio-diciembre 1993.

COUTINHO, Edilberto. A lugar algum. O jogo terminado. Rio de Janeiro: José Olympio, 1983, p.60-62.

DA MATTA, Roberto. Carnavais, malandros e outros heróis: para uma sociologia do dilema brasileiro. Rio de Janeiro: Zahar, 1978.

EDELWEISS, Ana Maria de Bulhões Carvalho. 6 X 4: Máscaras do narrador na obra de Silviano Santiago. Rio de Janeiro: UFRJ, 1997. (Tese de doutorado).

LOPES JÚNIOR, Francisco Caetano. A estória da bistória: questões de crítica cultural nos romances de Manuel Puig (El beso de la mujer araña), Silviano Santiago (Stella Manhattan), e José Cardoso Pires (Balada da Praia dos Cães). Tese de doutorado, University of Pittsburgh, 1988.

LOPES JÚNIOR, Francisco Caetano. Uma subjetividade outra. In: REIS, Roberto (Org.). Toward Socio-Criticism: Selected Proceedings of the Conference "Luso-Brazilian Literatures, A Socio-Critical Approach”. Tempe: Arizona State University, Center for Latin American Studies, 1991, p.67-75.

MIRANDA, Wander Melo. Corpos escritos: Graciliano Ramos e Silviano Santiago. São Paulo: EDUSP; Belo Horizonte: Editora UFMG, 1992. 
PEREIRA, Maria Antonieta. A tela e o texto - literatura e trocas culturais no Cone Sul. Comunicação apresentada no "Colóquio Trinacional - A Posição da Literatura no Âmbito dos Estudos Culturais", realizado em B. Horizonte, UFMG, em junho de 1998.

SANTIAGO, Silviano. Nas malhas da letra: ensaios. São Paulo: Companhia das Letras, 1989.

SANTIAGO, Silviano. Stella Manhattan. Rio de Janeiro: Rocco, 1985.

SANTIAGO, Silviano. Stella Manhattan. 2. ed. Rio de Janeiro: Rocco, 1991.

SANTIAGO, Silviano. Viagem ao México. Rio de Janeiro: Rocco, 1995.

SANTIAGO, Silviano. O narrador pós-moderno. Revista do Brasil, v.2, n.5 p.4-13, 1986.

SANTIAGO, Silviano. O narrador pós-moderno. Nas Malhas da Letra: Ensaios. São Paulo: Companhia das Letras, 1989, p.38-52.

SONTAG, Susan. Notes on "Camp". A Susan Sontag Reader. New York: Farrar, Straus, Giroux, 1982, p.105-119.

SOUZA, Eneida Maria de e MIRANDA, Wander Melo (Orgs.). Navegar épreciso: escritos para Silviano Santiago. Belo Horizonte: Editora UFMG; Salvador: EDUFBA; Niterói: EDUFF, 1997.

SÜSSEKIND, Flora. Ficção 80: Dobradiças e vitrines. Revista do Brasil, v.2, n.5, p.82-89, 1986.

\section{Resumo}

Este artigo pretende analisar o papel do espetáculo e do voyeurismo em Stella Manhattan de Silviano Santiago

\section{Abstract}

This paper presents an analysis of the importance of shows and voyeurism in Silviano Santiago's Stella Manhattan. 